\title{
AN EVALUATION OF THE PURPOSES OF RESEARCH IN SOCIAL WORK
}

\section{Herman Strydom}

\section{INTRODUCTION}

Different authors have varying opinions on what the purposes of research should be called. The terminology used in scientific writing should be understood to have a similar meaning by the various members of a particular profession or subject group. The main aim of this article is to provide clarity on various viewpoints and to delineate what can be considered the various purposes of research in social work. This article thus aims to study the various opinions and endeavours to describe and formulate the author's own viewpoint on this issue.

Hopefully this article will serve the purpose of starting a discussion on research methodology in social work in general. Although the purposes of research as indicated in this article may be generalisable to other subject groups, the author is first and foremost a social worker and can therefore have an opinion only on social work research. The textbooks on social work research are rather limited and therefore publications from the broader field of social science research will also be consulted in this article.

Before the design of a study can be developed, the purpose or purposes of the study should be formulated. Although some authors see purposes as part of the design, the purposes will be described separately for the sake of clarity, bearing in mind that they are part and parcel of the total research process. In this article a definition of "purposes" will be given, followed by a description of the various purposes of research, namely exploration, description, explanation, evaluation, intervention and participatory action research.

\section{DEFINITION AND PROBLEM STATEMENT}

A study normally starts with an initial idea or topic, which may be more or less clearly defined. These initial vague ideas may then develop by way of systematic review into more specific questions which assist the researcher in gaining clarity regarding the intellectual puzzle (Ritchie \& Lewis, 2003:48). Gilbert (2008:58) adds that the formulation of a research question should lead to the research methods, including the purposes and design of the study, and then followed by the total research project.

According to Babbie and Mouton (2010), Monette, Sullivan and DeJong (2011), Royse (2011), Rubin and Babbie (2010) and Thyer (2010), the research process basically consists of six steps, namely problem statement and research questions, research method, data collection, data analysis, interpretation of data and report writing. The purposes of research can be seen as part of step two, research method, in which the kind of research, the approach to research, the design, participants/subjects, measuring instruments, the procedure, ethical aspects and manner of data analysis can be distinguished. To decide on the purpose/s of research will then guide the design, the 
measuring instrument, the procedure, and data analysis to be followed in the study - this should follow a logical sequence, whether the study adopts a quantitative, qualitative or mixed-method research approach.

This article's main aim is to gain clarity on the various viewpoints, to delineate what can be considered the various purposes of research in social work, and to make a contribution to the field of social work. From studying various viewpoints on research purposes the author will endeavour to formulate his own viewpoint on this issue. The purposes of research have been described differently by different authors. A distinction can be drawn between the different kinds of knowledge (Alasuutari, Brickman \& Brannen, 2009:44), research strategies (Gravetter \& Forzano, 2003:131-135; Gravetter \& Forzano, 2012:159-167), research designs (Morris, 2006:20-37), objectives (Fouché $\&$ De Vos, 2011:94; Gilbert, 2008:512) and purposes of research or research questions (Babbie, 2013a:90-92; Babbie \& Mouton, 2010:79-81; Engel \& Schutt, 2013:17; Royse, 2011:27-29). The terms research designs, strategies, purposes, objectives, goals or aims are thus used interchangeably by various authors. In order, for instance, to explore, describe or explain a situation can be regarded as a purpose of research more so than any of the other terms. After a thorough study of available literature, the author finds the term "purposes of research" seems to be the most acceptable one and it is therefore used in this article.

\section{VARIOUS RESEARCH PURPOSES}

De Vaus (2002:1-3) distinguishes between only two kinds of research purposes, namely descriptive and explanatory research, while Cozby (2009:7) distinguishes four, namely description, prediction, causes of behaviour and explanation. McBurney (2001:12-16) distinguishes between description, discovering laws and the search for causes. Babbie (2013b:42-43), Babbie and Mouton (2010:79-84), Morris (2006:20-37) and Royse (2004:25) mention exploration, description and explanation as the three most common purposes of research. An evaluative purpose is added to these by Engel and Schutt (2013:18-21).

Fouché and De Vos (2011:94-99) say that research objectives are the specific steps one has to take to achieve the goal of the study and they include exploration, description, explanation, correlation, evaluation, intervention and action research. Correlational research, according to Fouché and De Vos (2011:96), is often used as a first step towards explanatory research with a view to determine whether a relationship exists between two variables without focusing on a cause-effect relationship between variables, but rather on the importance of the relationship. The distinction drawn between correlational and explanatory objectives is to my mind not clear: hence correlational objectives will not be distinguished as part of the aim of this article. An intervention purpose can be distinguished as one of the purposes of research and is directed at shedding light on, or providing possible solutions to, practical problems (Fouché \& De Vos, 2011:98). On the other hand, an evaluation and intervention purpose for research can also be integrated, because evaluation can be regarded as one of the steps of intervention research. Evaluation research can, however, be an independent purpose; therefore intervention and 
evaluation can be distinguished as being two separate categories that can be closely linked in one process. Participatory action research, also known as action research, in which the involvement of all the participants in a community is crucial in order to empower them and to lead to social and political action, will be distinguished as the sixth purpose of research.

More than one purpose can be delineated for the same study, but one will normally dominate a particular study (Neuman, 2006:33). Blaikie (2007:7-8) and Maree (2007:11) add that it is possible to combine exploratory, descriptive and explanatory purposes within a single research project, in the particular order given. Alston and Bowles (2003:34) say that most studies contain elements of all three purposes and that it depends on the nature of the research problem and the state of knowledge in the field (Blaikie, 2007:8). They can be discussed separately, although they are three interrelated aspects of the same sub-goal (McBurney, 2001:12). Exploratory, descriptive and explanatory purposes can be linked to the other three and can become sub-sections of evaluation, intervention or participatory action research. Within, for instance, an intervention purpose to develop and evaluate new technology, exploratory, descriptive and explanatory purposes can be delineated.

The first part of a study may begin with a concern to describe a particular phenomenon such as juvenile delinquency, including a description of who juvenile offenders are most likely to be, their backgrounds and their kinds of offences. If one further wishes to include a goal of examining various causes of juvenile delinquency, it becomes explanatory (Alston \& Bowles, 2003:34). Blaikie (2007:28) adds that questions have a sequence where "what" questions normally precede "why" questions, and answers to both of these two (what and why) precede "how" questions. Research questions state a research problem in a manner that can be investigated and that defines its nature and scope. Questions can assist in making choices regarding the focus and direction of research and in delimitating its boundaries clearly. Furthermore, manageability of the study can be achieved and a successful outcome anticipated.

In this article the following purposes of social work research will be distinguished in accordance with the viewpoints of various authors, namely exploration, description, explanation, evaluation, intervention and participatory action research.

\section{Exploratory research}

Marlow (2005:334) defines exploratory research as follows: "A form of research that generates initial insights into the nature of an issue and develops questions to be investigated by more extensive studies." Exploratory research is often a prelude to a more detailed study, but it can also be an important form of research in its own right (Alston \& Bowles, 2003:34). Engel and Schutt (2010:9-10) and Engel and Schutt (2013:18-19) say that exploratory research enquires into the circumstances in a community, how people get along in their setting, what meanings they give to their actions and what concerns them. In exploratory research large amounts of unstructured information are normally collected in order to explore a new topic, or to be responsive to new concerns by breaking new ground through delving into new problem areas, to work 
on topics about which very little information is available and to gain a broad understanding of a situation, community or person (Bless \& Higson-Smith, 2000:41; Glicken, 2003:267; Mitchell \& Jolley, 2010:550-552; Royse, 2011:27).

Babbie (2013a:90-91), Ginsberg (2001:157) and Pierson and Thomas (2010:440) add that an explorative purpose does not only apply to new concerns, in other words starting to familiarising yourself with the topic and to gain an initial understanding of a topic. Exploration is also appropriate for more persistent phenomena, for testing the feasibility of undertaking a more extensive study, for developing the methods to be employed in the study and for generating more focused research questions and hypotheses for additional investigations (Babbie, 2013a:90; Babbie \& Mouton, 2010:79; Royse, 2011:27; Struwig \& Stead, 2001:7).

Dane (2011:7) and Rubin and Babbie (2010:41) say that for an exploratory purpose the researcher can even attempt to determine whether or not a phenomenon exists or to endeavour to gain a beginning familiarity with the topic and it can be used in qualitative, quantitative and mixed methods research. Grinnell (2001:241) and Rubin and Babbie (2011:134) consider exploratory work to lie at the lowest level of the continuum of knowledge, which seldom provides satisfactory and conclusive answers to research questions. They might, however, hint towards an answer, and their concept formulation and findings are not always conclusive or definite and are on a small scale, thus lacking representativeness (Babbie, 2013a:91; Sarantakos, 2000:7). The researcher's goal is to formulate more precise questions for future research to answer.

Exploration is often the first stage in a sequence of phases for the same study in order for the researcher to know enough to design and execute a more systematic and extensive study, and to uncover generalisations and develop hypotheses that can be investigated and tested later (Grinnell, 2001:241). Everything the researcher finds in exploratory research might seem to be potentially important for the study - the steps at this stage are not necessarily well defined and the direction of the enquiry might change frequently. Researchers must be creative, open minded and flexible while adopting an investigative view in exploring all sources of information. Creative questions should be posed and advantage should be taken of serendipity factors that might influence or change the situation, which might have wider implications.

Qualitative techniques, which are almost always inductive in nature, are frequently used for gathering data for exploratory studies (Adler \& Clark, 2008:12; Neuman, 2006:3334; Sarantakos, 2000:7). Babbie (2010:92) and Struwig and Stead (2001:7) mention the study of secondary sources of information, focus groups, in-depth interviews and an analysis of selected cases as data-collection methods. Quantitative data in the exploratory paradigm are mostly gathered in a needs assessment fashion which focuses on large-scale surveys. Lewis-Beck, Bryman and Liao (2004:966) add that "what" questions can also require a descriptive answer and are directed at discovering and describing the characteristics of some social phenomenon such as age and sex. "Why" questions ask for either the causes of, or the reasons for, the existence of characteristics or regularities, and are concerned with the understanding or explaining of the 
relationships between events or processes. "How" questions are concerned with bringing about social change and with practical outcomes and interventions. "What" questions normally precede "why" questions, and "why' questions normally precede "how" questions.

We need to know what is going on before we can explain it, and we need to know why something behaves the way it does before we can be confident about introducing an intervention to change it. Most research projects will include only one or two types of research questions, most commonly 'what' and 'why', and some research may deal with only "what" (Lewis-Beck et al., 2004:966). The formulation of research questions is the most critical and even perhaps the most difficult part of any research design. The role of the hypothesis is to provide tentative answers to "why" and sometimes "how" questions. Hypotheses are not appropriate for "what" questions - the research will eventually produce an answer to "what" questions in due course and guessing is of no assistance in this regard (Lewis-Beck et al., 2004:967).

\section{Descriptive research}

Grinnell (2001:248) considers descriptive research to lie at the midpoint of the knowledge continuum. Much social research is descriptive in nature and uses a variety of data-gathering techniques (Neuman, 2006:34-35). Marlow (2005:333) defines descriptive research as follows: "A process of recording and reporting phenomena; not primarily concerned with causes." Dane (2011:8), DePoy and Gilson (2008:71), Ginsberg (2001:157), Pierson and Thomas (2010:440) and Royse (2011:27) see descriptive studies as larger-scale numerical efforts that attempt to characterise, for instance, age, income and family size, to understand, to illuminate and to gain a detailed picture of patterns of a particular group, such as the homeless, to differentiate them from other phenomena, or to accurately describe programme activities.

Engel and Schutt (2010:9), Engel and Schutt (2013:18) and Morris (2006:96) add that descriptive questions are normally overarching and involve the gathering of facts, for example: "What is your daily experience of being homeless"; "How many are homeless and what are the needs of homeless people?" Adler and Clark (2008:14), Marlow (2005:32) and Rubin and Babbie (2010:41-42) refer to large quantitative studies in which survey research within the correct sampling framework is attempted. This kind of data will normally be displayed in graphs, tables, frequency distributions, scatter grams and circle diagrams (Gomm, 2009:92).

On the other hand, Barker (2003:116), Grinnell and Unrau (2008:493-494) and Wolcott (2001:31) see descriptive data as being more of a qualitative nature and presented in the form of narrative interviews, focus groups and participant observation in order to gain a more dense description of phenomena and their deeper meanings by way of describing the setting, what it is like to walk in the shoes of the homeless, and to obtain details about their environment, interactions and the meanings they attach to their community (Rubin \& Babbie, 2005:125).

The viewpoints of Marlow (2005) and Rubin and Babbie (2010) are thus in contrast with the viewpoints of Adler and Clark (2008), Gomm (2009) and many others who see 
descriptive research on the quantitative level only. From this discussion it is obvious that it is not a matter of either/or but rather that both quantitative and qualitative data can be gathered from a descriptive approach (Babbie, 2010:80-81; Babbie \& Mouton, 2010:8081; Struwig \& Stead, 2001:8). One can, however, say that descriptive studies would focus more on quantitative data where large numbers of participants are involved because one wants to know, for instance, how many of the homeless people are single parents, what their age categories are and the number of children they have.

Cozby (2009:7) and Jackson (2011:16) state that careful observation is the first goal when describing events. The researcher might have a more highly developed idea of a social phenomenon and wants to describe it in terms of, for instance, the demographic characteristics of the population (Struwig \& Stead, 2001:9). In reporting qualitative data there will be many occasions on which descriptive data will be needed to display the evidence collected - one will have to decide how best to display the original material in relation to the categories and classes of data found and how much explanation to give regarding the categorisation and classification that has been developed (Ritchie \& Lewis, 2003:302-303).

In descriptive research a body of knowledge already exists for which we can produce additional knowledge, perhaps at a higher level of importance (Glicken, 2003:15). In descriptive studies one might find a relationship between two variables, but still not be able to say why this relationship exists (Mitchell \& Jolley, 2010:205-209), because no explanation has yet been given. Babbie (2010:93) and Barker (2003:116) add that in descriptive studies there is thus no indication of determining cause-and-effect relationships, but the aim rather is to describe situations and events and to determine accurately what the real situation is.

Barker (2003:116), Gravetter and Forzano (2003:131), Mertens (2009:145) and Monette et al. (2011:4) see this kind of research as an attempt to discover facts or to describe reality accurately as it exists naturally in order to gain an overview of the current status of a situation. Descriptive research presents a picture of the specific details of a situation, social setting or relationship (Salkind, 2000:192). Descriptive and exploratory studies have many similarities and often merge in practice. The researcher begins with a well-defined subject and conducts research to describe the phenomenon accurately, and the final outcome of a descriptive study should be a detailed picture of the subject. Mertens (2009:146) states that descriptive data are typically derived from the collection of needs assessment data before an intervention takes place, or when a potential revision of a programme may be planned.

\section{Explanatory research}

Engel and Schutt (2010:10-11), Jackson (2011:16), Marlow (2005:334) and Pierson and Thomas (2010:440) explain that explanatory research seeks to identify causes, to ascertain causality between factors and to determine effects on behaviour of a social phenomenon, and to predict how one phenomenon will change or vary in relation to another variable, for example, to understand and explain the causes of a social condition such as homelessness. This should lead to explaining why events occur and to building, 
elaborating, extending, testing or revising a theory (Babbie \& Mouton, 2010:81; Neuman, 2006:35-36; Sarantakos, 2000:7).

The following questions can be asked, for instance: Why do people become homeless and does the unemployment rate influence the frequency of homelessness? (Engel \& Schutt, 2013:19). Thyer (2010:18) adds that explanatory research aims at developing and testing theory in a particular field of study. Engel and Schutt (2013:19-20) consider explanatory research to be the ultimate goal of science and at the highest level of the knowledge continuum.

Explanatory studies are normally experimental in nature, where hypotheses can be tested and comparison groups used. A hypothesis such as the following can be mentioned as an example, namely that there is a link between people who misuse alcohol as adults and their having been victims of childhood abuse (Royse, 2004:25). Unlike descriptive research, which tends to focus on how things are, the goal of explanatory research is to explain why things are the way they are (Adler \& Clark, 2008:14; Babbie, 2013a:92). Explanatory research normally builds on exploratory and descriptive purposes, and goes beyond focusing on a description of a topic or providing a picture of it.

An explanatory purpose can be useful in programme evaluation in order to make statements about the influence of the programme on participants and it focuses on causal relationships between the independent variable (the intervention) and the dependent variable (change in the behaviour of a group) (Ginsberg, 2001:158). To describe the voting intentions of an electorate is descriptive, but when reporting on why some people will vote for candidate A and others for B is an explanatory activity (Babbie \& Mouton, 2010:81). Rubin and Babbie (2005:125) say that when one investigates how often and what forms of abuse are experienced by women, the study will be descriptive, but when one wants to know why battered women repeatedly return to live with their abusers, the study becomes explanatory in nature. Rubin and Babbie (2010:42) say that this third purpose of research is to explain things - explanatory studies can also follow a quantitative, qualitative or mixed-methods approach.

Glicken (2003:267) explains explanatory research as: "The type of research that attempts to provide meaningful and accurate conclusions from the considerable amount of information already available." When a researcher already knows a great deal about an issue and has a description of it, the "why" question might arise and one might want to explain why things are the way they are and to demonstrate the factors needed to produce or eliminate a behaviour pattern (Jackson, 2003:13). A causal connection between the independent and dependent variable can thus be established in explanatory research (Grinnell, 2001:255). Grinnell (2001:255 considers explanation to lie at the highest level of the knowledge continuum, to have the most rigid requirements and to be the most able to produce results that can be generalised to other people and situations and are therefore most valid and reliable.

Explanatory research tends to be deductive and thus quantitative in nature. Its intention is to generate data about relatively large numbers of cases making use of statistical analysis in the interpretation of the data (Adler \& Clark, 2008:14-15). An explanatory 
purpose can, however, also be inductive; thus it entails gathering qualitative data. Displaying explanatory evidence in qualitative research can be difficult, especially when writing up qualitative data. The following can assist in doing explanatory research from a qualitative viewpoint, namely giving explicit reasons for a phenomenon, presenting the underlying logic or common sense, drawing on other theoretical or empirical evidence, and describing wider applications for this new programme (Ritchie \& Lewis, 2003:309311). As new evidence is gathered, previous explanations of behaviour must often be discarded or revised (Cozby, 2009:9).

\section{Evaluation research}

Evaluation research assesses a particular intervention or practice in real-life situations in the social world (Bryman, 2008:693). Evaluation research focuses on the best allocation of scarce sources, on accountability and on improving a current programme/service (Fouché, 2011:452). Evaluation research can assess, for instance, the aims, the design, funding possibilities, implementation and applicability of social interventions in order to determine whether an intervention has produced the intended results. It can be conducted by adopting a qualitative, quantitative or mixed-methods approach (Fouché \& De Vos, 2011:98; Royse, Thyer \& Padgett, 2010:12).

Barker (2003:149), Engel and Schutt (2010:11-12), Engel and Schutt (2013:20), Monette et al. (2011:4) and Royse et al. (2010:1) say that evaluation research is concerned with programme evaluation or practice evaluation and seeks to determine the effects of social policies and the impact of programmes and interventions in a systematic manner describing the clients using a particular programme, evaluating the effectiveness of a particular programme, estimating causal effects and monitoring the progress of clients.

Mamburu (2004) used evaluation research in his study on the evaluation of the Poverty Relief Programme in the Limpopo Province within the context of the Reconstruction and Development Programme from a social work perspective. Both quantitative and qualitative data-gathering methods were combined in a mixed-methods strategy. Mamburu (2004) used document analysis of the RDP documents and semi-structured interviewing with 12 key informants in executive positions regarding this document as the qualitative methods. He also used self-administered questionnaires within the probability sampling framework with community development officers involved in RDP in the Limpopo Province as the quantitative method.

Components of exploratory, descriptive and explanatory purposes of research may be present in evaluation research (Rubin \& Babbie, 2010:42; Rubin \& Babbie, 2011:135). For instance, if one asks practitioners in a qualitative open-ended fashion to recall techniques they have employed that seemed to be the most or least effective in achieving treatment goals, one would be conducting an exploratory evaluation to generate tentative insights as to what ways of intervening might be worth evaluating further. A quantitative descriptive community survey might be done to evaluate the problems residents have and the services they say they need. A descriptive study might also evaluate whether services are being implemented as intended. 
An explanatory analysis might also be done to evaluate whether factors such as ethnicity explain why some residents are more likely than others to utilise services. If one can determine and access all possible variables in a situation that might have influenced the programme, for instance, one will have an explanatory evaluation (Rubin \& Babbie, 2010:42). Evaluative studies might also ask whether social policies, programmes or services are effective in achieving their stated goals - again, this can be done in an exploratory, descriptive or explanatory manner. Whether quantitative, qualitative or mixed-method research is used in a particular study, one must be clear about the purpose or purposes of the intended study and the possible outcomes of the study (Alston \& Bowles, 2003:35).

The assumption that a programme exists is crucial to evaluation research and it does not matter whether a particular programme had been developed long ago and by someone else (Fouché, 2011:450). Evaluation research can also be seen as part of intervention research - as a matter of fact evaluation is one of the steps in intervention research. The main difference between evaluation research and intervention research lies in the focus. Evaluation research focuses on the evaluation of an existing programme, while intervention research focuses on the total process of developing a programme, evaluating it and then disseminating it.

Three sections of evaluation research can be distinguished, according to Fouché (2011:453-464), namely formative evaluation, process evaluation and summative evaluation. Formative evaluation focuses on doing needs assessment to try and maximise the chances of the programme being successful and where an attempt has been made to improve the design and the development of a programme. In process evaluation the emphasis is on the evaluation of the process of programme development and the constant monitoring and improvement of the programme. Summative evaluation, on the other hand, evaluates the impact, outcomes and efficiency of the programme, the communication of best practices to people involved in similar situations; it focuses on accountability-driven evaluations and the responsible use of public funds to reach the desired results. Process evaluation tends to be exploratory or descriptive in nature within the quantitative or qualitative paradigm, while outcome evaluation tends to focus on explanatory objectives in order to examine causal links between actions (D'Cruz \& Jones, 2010:93-94).

\section{Intervention research}

Intervention research can be considered to be applied research where new technology is developed, evaluated and disseminated with the purpose to be of practical value (Fraser, Richman \& Galinsky, 2009:17). De Vos and Strydom (2011:475) define intervention research as research done for the purpose of formulating, creating and testing innovative programmes in preventing or alleviating problems in society and maintaining or raising the quality of life. Intervention research follows a certain process in which both the quantitative and qualitative research paradigms can be used, making it an excellent way of doing mixed-methods research. 
Six phases with a number of steps in each can be distinguished in the intervention research model, namely problem analysis and project planning, information gathering and synthesis, design, early development and pilot testing, evaluation and advanced development and dissemination (De Vos \& Strydom, 2011:476-489). Problem analysis and project planning as the first step of the model identify and involve clients, gaining entry into and cooperation from settings, identifying concerns of the population, analysing identified problems, and setting goals and objectives for the research project. Information gathering and synthesis, as the second step, use existing information sources by studying natural examples and identifying functional elements of successful interventions/models.

In the third step the design is undertaken with the focus on designing an observational system and specifying procedural elements of the intervention. Early development and pilot testing as the fourth step focuses on developing a prototype of preliminary intervention, conducting a pilot test and applying design criteria to the preliminary intervention concept. Evaluation and advanced development can be distinguished as the fifth step, where an experimental design is developed; the data are collected and analysed. Replicating the intervention under field conditions and refining the intervention is then undertaken. In the last instance, dissemination takes place, where the product for dissemination is prepared, potential markets for the intervention are identified, a demand for the intervention is created, appropriate adoption is advocated, and technical support for possible adopters of the programme is provided.

Jansen van Rensburg (2011), in her study on an empowerment programme for personnel and retired volunteers at a service centre for the aged, used intervention research to develop, evaluate and disseminate programmes for both of these target groups. Likewise, Olivier (2009) used intervention research to develop, evaluate and disseminate an HIV and Aids programme to prepare adolescents for the possible death of their caregivers.

As a further innovative development to the existing intervention models, Strydom, Steyn and Strydom (2007) propose an adapted intervention research model to bridge the gaps in the existing models (DR\&U and IR) and to serve a more user-friendly purpose in doing intervention research, especially when an initial needs assessment is done, after which the programme is developed, evaluated and eventually disseminated. This new model is a seven-phase model consisting of problem delimitation, methodology, analysis, development, evaluation, adaptation and dissemination (Strydom et al., 2007:337-341). Delimitation as the first phase focuses on problem identification, problem formulation, aim/objectives and the pilot study. Methodology forms the second phase during which the kind of research, the approach, the design, the model, the procedures and data-gathering methods are established.

In the third phase analysis takes place with the emphasis on a needs assessment, data gathering, data analysis and report writing. Development forms the fourth phase of the model, when the development of the programme takes place. Evaluation as the fifth phase focuses on programme presentation, data gathering, data analysis and report 
writing. The sixth phase is called adaptation during which adaptations to the preliminary programme are made in order to make it a user-friendly programme. Dissemination as the seventh phase focuses on the marketing of the new technology, writing the final report, the dissemination into manuscripts and the distribution of the final product. When undertaking intervention research the researcher must not only be an expert in the field of study but must also understand the practice situation (Fraser et al., 2009:4).

\section{Participatory action research}

A distinction can be drawn between participatory action research and action research. In participatory action research (PAR) the objective is to involve the total community in collaborative efforts to diagnose a problem and to encourage collaboration between researchers and participants in changing, improving or solving the specific identified problem in that community (Bryman, 2008:382; D'Cruz \& Jones, 2010:88; Jupp, 2009:2; Shaw, Briar-Lawson, Orme \& Ruckdeschel, 2010:68-69). Action research as such focuses more on the process of critical reflection, enquiry and action carried out by a professional in his/her field of practice (Costello, 2004:4). The author's personal opinion is that there is basically very little difference between evaluation research and action research - both indicating research to evaluate practice and to suggest improvements to be made in future.

For this discussion the term "participatory action research" will be used, meaning to involve all participants in a community or setting in the total research process. PAR is thus research being done to propose action to be taken and the participation of the community members in a manner that enhances empowerment and self-determination to solve a problem or problems in a particular community with the eventual aim to improve practice (Bryant \& Charmaz, 2008:400-401; McNiff \& Whitehead, 2012:14). PAR can be seen as a complex process, in which a close relationship between scientific reflection, theory development and practical action should be maintained (Bryant \& Charmaz, 2008:400; Shaw et al., 2010:69). PAR is done by some researchers because of its focus on involving the community in the diagnosis of, and finding solutions to, their own problems as opposed to forcing or suggesting solutions for other people's problems (Bryman, 2008:382).

McNiff and Whitehead (2012:10-11) say that there is no consensus on taking action and doing research in one process, and some supporters of PAR focus on one without much emphasis on the other. The question can then be posed: Who does the action and who does the research? The PAR researcher might become the community worker when the research project is concluded, but it remains the author's view that PAR calls for a team effort among the researcher/s, the community leaders and the community worker/s, with specific tasks assigned to each participant. If community members can become actively involved and mobilised in an interactive manner in improving their own situation and their own wellbeing, they become empowered and committed towards achieving common goals for their community, which motivates them to take charge and become self-reliant in future regarding their own and the community's mutual situation (Strydom, 2011:493). 
A plan of critically informed action must be developed in order for the community members to work towards a solution; the effects of the action must be monitored and reflected upon in order to do further planning for various further cycles of action following on each other (Bryant \& Charmaz, 2008:399; D'Cruz \& Jones, 2010:88-89). Normally one would do a comprehensive needs assessment of the total community before one can delineate various projects, for instance, for young children, the aged or the jobless. Both the quantitative and qualitative paradigm can be utilised in a mixedmethod approach. Even when using qualitative measures, the needs of the total community must be taken into consideration - small individual research projects might be initiated simultaneously within the ambits and objectives of the total project such as a reading group for the illiterate, storytelling for children, focus groups with alcoholic men, poverty, interviewing the aged, a survey among the youth, and general observation.

It is important to become acquainted with a particular community before any action can be taken. The PAR process can be applied in the workers' own workplace by workers from the particular organisation or in an external organisation or community. When done in the workplace by its own workers, questions may be raised about objectivity, the social order and the values of the persons and organisation involved, and what the definition of the workplace is (McNiff \& Whitehead, 2012:39). A community must never be chosen for pragmatic reasons, and proper entry through the correct channels must be sought. It is advisable that a research team get to know the community over time before really getting into doing research and planning projects on what the researcher sees as the problems in that community. In this way the real needs of a community can be uncovered and properly addressed. Definite goals and objectives must be stated in advance.

PAR requires proper planning, negotiation and regular evaluation throughout the project. The action plan decided on should be explained within the various sub-sections of the total project. Eventually, the action outcomes must be evaluated in order to determine which outcomes were achieved and which not, and what can be done about those not achieved (Strydom, 2011:499-502). The researcher/s in PAR should take all aspects into consideration, such as gaining proper entry into the community, involving the total community, negotiating and planning with the leaders of the community, while still remaining an objective researcher. This calls for a special kind of senior researcher with many organisational and administrative skills besides only research skills.

\section{SUMMARY}

Although there are different opinions on what the purposes of research entail, the author has endeavoured to study the various viewpoints and to formulate a personal opinion on this topic. Before the design of a study can be developed, its purpose or purposes should be formulated. Although some authors see these purposes as part of the design, for the sake of clarity the purposes were described separately here, bearing in mind that they are part and parcel of the total research process. In this article a definition was given of the notion of purposes, followed by a description of the various purposes of research, 
namely exploration, description, explanation, evaluation, intervention and participatory action research.

\section{REFERENCES}

ADLER, E.S. \& CLARK, R. 2008. How it's done: an invitation to social research. London: Thomson Wadsworth.

ALASUUTARI, P., BICKMAN, L. \& BRANNEN, J. 2009. The SAGE handbook of social research methods. London: Sage Publications.

ALSTON, M. \& BOWLES, W. 2003. Research for social workers. London: Routledge Taylor \& Francis Group.

BABBIE, E. 2010. The practice of social research. London: Wadsworth Cengage Learning.

BABBIE, E. 2013a. The practice of social research. London: Wadsworth Cengage Learning.

BABBIE, E. 2013b. Social research counts. London: Wadsworth Cengage Learning.

BABBIE, E. \& MOUTON, J. 2010. The practice of social research. Cape Town: Oxford University Press.

BARKER, R.L. 2003. The social work dictionary. Washington: NASW Press.

BLAIKIE, N. 2007. Approaches to social enquiry: advancing knowledge. London: Polity Press.

BLESS, C. \& HIGSON-SMITH, C. 2000. Social research methods: an African perspective. Cape Town: Juta Publishers.

BRYANT, A. \& CHARMAZ, K. 2008. The SAGE handbook of grounded theory. Los Angeles: Sage Publications.

BRYMAN, A. 2008. Social research methods. London: Oxford University Press.

COSTELLO, P.J.M. 2004. Action research. London: Continuum.

COZBY, P.C. 2009. Methods in behavioral research. Boston: McGraw Hill Higher Education.

DANE, F.C. 2011. Evaluating research: methodology for people who need to read research. Los Angeles: Sage Publications.

D'CRUZ, H. \& JONES, M. 2010. Social work research: ethical and political contexts. Los Angeles: Sage Publications.

DEPOY, E. \& GILSON, S. 2008. Evaluating practice: how to do good evaluation research in work settings. New York: Routledge Taylor \& Francis Group.

DE VAUS, D. 2002. Research design in social research. London: Sage Publications.

DE VOS, A.S. \& STRYDOM, H. 2011. Intervention research. In: DE VOS, A.S., STRYDOM, H., FOUCHÉ, C.B. \& DELPORT, C.S.L. (eds). Research at grass roots: 
for the social sciences and human service professions. Pretoria: Van Schaik Publishers, 473-490.

ENGEL, R.J. \& SCHUTT, R.K. 2010. Fundamentals of social work research. London: Sage Publications.

ENGEL, R.J. \& SCHUTT, R.K. 2013. The practice of research in social work. Los Angeles: Sage Publications.

FOUCHÉ, C.B. 2011. Evaluation research. In: DE VOS, A.S., STRYDOM, H., FOUCHÉ, C.B. \& DELPORT, C.S.L. (eds). Research at grass roots: for the social sciences and human service professions. Pretoria: Van Schaik Publishers, 449-472.

FOUCHÉ, C.B. \& DE VOS, A.S. 2011. Formal formulations. In: DE VOS, A.S., STRYDOM, H., FOUCHÉ, C.B. \& DELPORT, C.S.L. (eds). Research at grass roots: for the social sciences and human service professions. Pretoria: Van Schaik Publishers, 89-100.

FRASER, M.W., RICHMAN, J.M., GALINSKY, M.J. \& DAY, S.H. 2009. Intervention research: developing social programs. London: Oxford University Press. GILBERT, N. 2008. Researching social life. Los Angeles: Sage Publications.

GINSBERG, L.H. 2001. Social work evaluation: principles and methods. Boston: Allyn and Bacon.

GLICKEN, M.D. 2003. Social research: a simple guide. Boston: Allyn and Bacon. GOMM, R. 2009. Key concepts in social research methods. London: Palgrave Macmillan.

GRAVETTER, F.J. \& FORZANO, L.B. 2003. Research methods for the behavioral sciences. London: Thomson Wadsworth.

GRAVETTER, F.J. \& FORZANO, L.B. 2012. Research methods for the behavioral sciences. London: Wadsworth Cengage Learning.

GRINNELL, R.M. 2001. Social work research and evaluation: quantitative and qualitative approaches. New York: F.E. Peacock Publishers.

GRINNELL, R.M. \& UNRAU, Y.A. 2008. Social work research and evaluation: foundations of evidence-based practice. London: Oxford University Press.

JACKSON, S.L. 2003. Research methods and statistics: a critical thinking approach. New York: Thomson Wadsworth.

JACKSON, S.L. 2011. Research methods: a modular approach. New York: Wadsworth Cengage Learning.

JANSEN VAN RENSBURG, S.M. 2011. 'n Bemagtigingsprogram vir personeel en afgetrede vrywilligers van dienssentrums vir bejaardes. [An empowerment programme for personnel and retired volunteers at a service centre for the aged.] Potchefstroom: NWU. (PhD Thesis) 
JUPP, V. 2009. The SAGE dictionary of social research methods. London: Sage Publications.

LEWIS-BECK, M.S., BRYMAN, A. \& LIAO, T.F. 2004. The SAGE encyclopedia of social research methods (Volume 3). London: Sage Publications.

MAMBURU, D.N. 2004. Evaluation of the Poverty Relief Programme in the Limpopo Province within the context of the Reconstruction and Development Programme from a Social Work perspective. Pretoria: UP. (DPhil Thesis)

MAREE, K. 2007. First steps in research. Pretoria: Van Schaik Publishers.

MARLOW, C.R. 2005. Research methods for generalist social work. New York: Thomson Brooks/Cole.

McBURNEY, D.H. 2001. Research methods. London: Wadsworth Thomson Learning.

McNIFF, J. \& WHITEHEAD, J. 2012. All you need to know about action research. Los Angeles: Sage Publications.

MERTENS, D.M. 2009. Transformative research and evaluation. New York: The Guilford Press.

MITCHELL, M.L. \& JOLLEY, J.M. 2010. Research design explained. New York: Wadsworth Cengage Learning.

MONETTE, D.R., SULLIVAN, T.J. \& DEJONG, C.R. 2011. Applied social research: a tool for the human services. New York: Brooks/Cole Cengage Learning.

MORRIS, T. 2006. Social work research methods: four alternative paradigms. London: Sage Publications.

NEUMAN, W.L. 2006. Social research methods: qualitative and quantitative approaches. New York: Pearson Allyn and Bacon.

OLIVIER, K. 2009. An HIV and Aids group work programme empowering adolescents for the possible death of their caregivers. Potchefstroom: NWU. (PhD Thesis)

PIERSON, J. \& THOMAS, M. 2010. Dictionary of social work: the definitive A to $\mathbf{Z}$ of social work and social care. New York: McGraw Hill Open University Press.

RITCHIE, J. \& LEWIS, J. 2003. Qualitative research practice: a guide for social science students and researchers. London: Sage Publications.

ROYSE, D. 2004. Research methods in social work. London: Thomson Brooks/Cole.

ROYSE, D. 2011. Research methods in social work. New York: Brooks/Cole Cengage Learning.

ROYSE, D., THYER, B.A. \& PADGETT, D.K. 2010. An introduction to program evaluation. New York; Wadsworth Cengage Learning.

RUBIN, A. \& BABBIE, E.R. 2005. Research methods for social work. New York: Thomson Brooks/Cole. 
164

RUBIN, A. \& BABBIE, E. 2010. Essential research methods for social work. New York: Brooks/Cole Cengage Learning.

RUBIN, A. \& BABBIE, E. 2011. Research methods for social work. New York: Brooks/Cole Cengage Learning.

SALKIND, N.J. 2000. Exploring research. New York: Prentice Hall.

SARANTAKOS, S. 2000. Social research. South Yarra: Macmillan Education Australia.

SHAW, I., BRIAR-LAWSON, K., ORME, J. \& RUCKDESCHEL, R. 2010. The SAGE handbook of social work research. Los Angeles: Sage Publications.

STRUWIG, F.W. \& STEAD, G.B. 2001. Planning, designing and reporting research. Cape Town: Pearson Education South Africa.

STRYDOM, H. 2011. Participatory action research. In: DE VOS, A.S., STRYDOM, H., FOUCHÉ, C.B. \& DELPORT, C.S.L. (eds). Research at grass roots: for the social sciences and human service professions. Pretoria: Van Schaik Publishers, 491-506.

STRYDOM, H., STEYN, M.M. \& STRYDOM, C. 2007. An adapted intervention research model: suggestions for research and practice. Social Work/Maatskaplike Werk, 43(4):329-342.

THYER, B. 2010. The handbook of social work research methods. Los Angeles: Sage Publications.

WOLCOTT, H.F. 2001. Writing up qualitative research. London: Sage Publications.

Prof Herman Strydom, Dept of Social Work, North-West University (Potchefstroom Campus), Potchefstroom, South Africa. 